\title{
HACIA EL VIEJO CELOSO DE CERVANTES
}

Hace ya tiempo que en una serie de sólidos y autorizados estudios Georges Cirot demostró que los maridos celosos presentes en la obra de Cervantes pertenecen a una larga tradición literaria y folklórica, muy de moda, además, durante el Siglo de Oro, y que por lo tanto cualquier relación textual que se intente establecer a partir de ese tema ha de resultar necesariamente precaria e inconcluyente. Las fuentes que han sido aducidas son muchas, pero $\tan$ extensa y tan compleja es la enramada que forman que toda precisión se hace imposible. De ahí el acierto de Eugenio Asensio al señalar que por lo que respecta al entremés cervantino, "su originalidad no reside en la materia, sino en el modo de enfoque", añadiendo, sin embargo, que no por ello ha dejado de ser "día de fiesta para los buscadores de fuentes". Jean Canavaggio también se ha ocupado de reforzar el caso al afirmar que ni fuentes ni tradición "llegan a iluminar [...] la génesis del entremés cervantino" "2. Así prevenido y avisado, no he de seguir yo ahora tan desagradecida e infructuosa senda. Lo que me propongo, por el contrario, es ampliar el marco contextual de El viejo celoso y sugerir nuevas perspectivas intertextuales a otro nivel que el de sus fuentes. Permítaseme entonces declarar como premisa que la temática del entremés no se limita a los celos y que su sentido e interés, más allá de su comicidad, se centra en el otro factor de la ecuación de su título, es decir, en la edad del viejo y el tipo de relación que esta circunstancia supone.

Es de notar, en un principio, que en los cuentos medievales de la Disciplina clericalis o del Libro de los enxiemplos por abc, hacia los que apunta la tradición, el celoso es siempre mancebo. No se

1 Asensio 1982, pp. 19, 25.

2 Cannavaggio 1981 , p. 20. 
trata simplemente, pues, de celos y adulterio, sino que en $E l$ viejo celoso (y en El celoso extremeño) se dan unidos dos tópicos importantes que la crítica no se ha ocupado de deslindar suficientemente. Me refiero al del marido celoso y engañado, por una parte, y por otra al del viejo y la niña ${ }^{3}$. En el presente estudio me ocupo de precisar la importancia y significación del segundo de estos tópicos y, más particularmente, de analizar lo que la indiscutible presencia del tema concomitante del incesto añade a la festiva lección del entremés ${ }^{4}$. Para ello utilizo como contexto el horizonte de intereses y preocupaciones que de cara a El viejo celoso nos ofrecen el Diálogo entre el amor y un viejo de Rodrigo de Cota, la farsa de Gil Vicente, $O$ velho da horta, y finalmente el entremés anónimo titulado Entremés de un viejo ques casado con una mujer moza.

El Diálogo entre el amor y un viejo de Rodrigo de Cota aparece en el Cancionero general de Castillo (1511) y es reimpreso luego en 1569, ya en vida de Cervantes ${ }^{5}$. En tono y situación manifiesta un eco apreciable de las sabrosas peleas entre Don Amor y el Arcipreste. El viejo del Diálogo se retrae escarmentado del Amor y se esconde en una huerta seca y destruida, donde se encierra, además, en una pobre choza. Se alaba para empezar de su triunfo, de la supuesta invulnerabilidad que la edad le proporciona: "la edad y la razón / ya de ti me han libertado"' (p. 226). El Amor le responde culpando a la melancolía y alabando sus propios poderes: "De los hielos saco fuego,/ y a los viejos meto en juego, / y a los muertos resucito" (id.). El viejo todavía se defiende y le lanza a guisa de planto una letanía de familiares acusaciones:

\author{
El libre haces cautivo, \\ al alegre mucho triste, \\ do ningun pesar consiste \\ pones modo pensativo. \\ Tu con tu sentido ciego \\ pones alas en el vicio. \\ Tu destruyes la salud, \\ tu rematas el saber, \\ tu haces en senectud \\ la hacienda y la virtud \\ y el autoridad caer (p. 227).
}

3 Cf. Castro 1980, np. 133-136; y Casalduero 1974, p. 212.

4 Clamurro 1982, p. 317.

5 Fernández de Moratín 1848, p. 179. 
El amor justifica entonces su conducta y le promete renovado vigor y juventud, con lo que el viejo comienza a dejarse vencer:
Allégate un poco más;
tienes tan lindas razones
que sufrirte he que me encones
por la gloria que me das (id.).

La reconciliación tiene lugar punto seguido, y al deseado encuentro, entre desnudos abrazos, sucede con rapidez la confusión y la condena: "Seguirás estrecha liña/ en amores de una niña/ de muy duro corazón" (id.). Así engañado, al viejo le resta tan sólo pedir perdón por su pecado y vana esperanza, pero se permite una última gracia:
Si del precio del vencido
del que vence es el honor, yo de ti tan combatido no seré flaco, caído, ni tú fuerte, vencedor (id.).

De este Diálogo afírmó Moratín en sus Orígenes del teatro español lo siguiente: "es una representación dramática con acción, nudo y desenlace [... ] el estilo es conveniente, fácil y elegante; los versos tienen fluidez y armonía"'6. Y Merimée en su Historia añade que "it is, both in form and subject, one of the most graceful and perfect compositions of that age" 7 . A nosotros nos importa señalar, en ausencia de los celos, la presencia de varios factores significativos de cara a El viejo celoso: en primer lugar, la avanzada edad del enamorado, las precauciones que toma, el engaño y la caída que sufre y, por último, el escarmiento, en el que el amor se vuelve niña, es decir, la conversión del objeto deseado en instrumento de burla y castigo.

Nos encontramos ante una situación dramática en la que un viejo escarmentado, pero lujurioso aún, se atreve por vanidad y locura a ir en contra de los límites de su naturaleza, punto común y fundamental éste en todas las obras que nos ocupan. El castigo que recibe no es otro que sufrir el desamor de una niña: "Mira, malaventurado,/ que te deja a ti el pecado,/ tú no lo quieres de-

6 Idem.

7 Merimée 1930, p. 126. 
jar" (p. 227). Aunque la lección se presenta en términos claramente didáctico-morales, no está ausente la comicidad, la cual se desprende tanto de la situación de desequilibrio provocada por la edad e interés del viejo como de la acción y palabras. El exceso de confianza por una parte y el vano atrevimiento por otra, conducen al viejo a su fin como ejemplo de adonde llevan la locura de la lujuria, el desdecir del amor y el atentar contra lo natural ${ }^{8}$. A pesar de la alusión a la niña, doble objeto de pecado y castigo, la presencia del motivo del incesto en este caso apenas si se sugiere como tangencial condición del extremado y antinatural interés amoroso del viejo, merecedor así de frustración y burla.

La farsa de Gil Vicente data de principios del siglo XVI (1512). De nuevo aparece la huerta, ahora como una especie de disminuido locus amoenus en el que tiene lugar el abortivo encuentro amoroso, y de nuevo un viejo y una niña forman la inusitada pareja. El viejo de Gil Vicente es rico y honrado pero tiene la debilidad de no sólo enamorarse de la niña, sino que da en el extremo de perder por ella su hacienda. Le sirve en esto una alcahueta de corte celestinesco, Blanca Gil, que sabedora de su mal, le va sonsacando gradualmente su fortuna hasta que queda pobre, burlado y sin niña.

Desde el momento inicial del encuentro la niña, que no da otro motivo al amor del viejo sino el de entrar en su huerta, rechaza de plano sus requerimientos amorosos e intenta siempre hacerle consciente de lo ridículo de su pretensión y de la incongruencia existente entre su estado y deseos: "No veis que estáis ya muerto / y andáis contra natura?" ". Pero el viejo da en insistir y sufre consciente, más allá de toda razón:

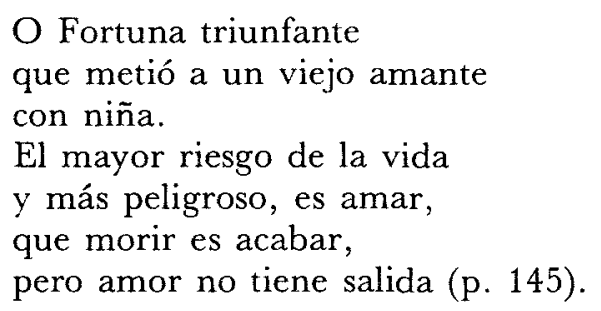

Al rechazo sigue luego el engaño, esta vez a cargo de la alcahueta, y los deseos del viejo van a parar de nuevo en desilusión y escarmiento:

8 Bigeard 1972, p. 148.

9 Gil Vicente s. a., pp. 146. 


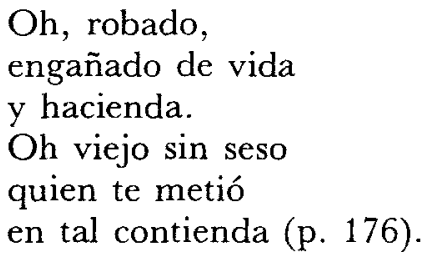

De particular interés, vis- $\dot{a}$-vis el celoso de Cervantes, es la actitud final de culpa y desengaño de que da muestras el viejo de la farsa: "Quiero buscar la muerte,/ pues que tanto mal busqué" (id.).

Observamos también aquí ciertos elementos que apuntan hacia el entremés cervantino. Puesto que la niña es inocente, el papel de burladora lo hace la vieja celestinesca. Los celos son algo velado, apenas sugerido, cuando el viejo aprende que la niña, a pesar de sus atenciones y regalos, se ha casado con otro. Pero de nuevo, son la edad y los tan extremados como inapropiados deseos de posesión del viejo, que excede así su condición y naturaleza, lo que caracteriza su frustrado interés y ocasiona su burla y castigo.

La última obra qué estudiamos, el anónimo Entremés de un viejo ques casado con una mujer moza, de finales del siglo XvI, se acerca más a El viejo celoso de Cervantes ya que aparece ahora de lleno el tema de los celos, el cual viene así a añadirse al interés amoroso incongruente y contra naturaleza visto en las dos piezas anteriores. De ahí que podamos afirmar que la constante en estas obras no son los celos, sino el tópico del viejo y la niña, es decir, la edad del viejo, y lo que ésta conlleva en cuanto a la naturaleza y objeto de su deseo, es decir, la relación seudoincestuosa entre él y la niña, a cuyo establecimiento aspira. Pero antes de seguir adelante, veamos con un poco más de detalle el asunto de este gracioso entremés.

El viejo en esta ocasión, también rico, se marcha a inspeccionar su hacienda encomendando su mujer al cuidado de un bobo. Su temor declarado es que un tal Chuzón, otro bobo, se atreva a servir como alcahuete de un licenciado de nombre Albaida. Su caso es más avanzado que el de sus antecesores, y si desde el inicio vemos que ha logrado conseguir lo que los otros no pudieron - muy para su pesar - también estamos conscientes de que la seguridad y la complacencia han dado paso con ello a la duda y a los celos. He aquí su queja: "Malaya el hombre, malaya el hombre que siendo viejo se casa con mujer loca y moza, y mal haya 
el hombre que tiene mujer moza y hermosa y consiente que médico mozo le tome el pulso!' 10 .

La niña, como la Lorenza de Cervantes, tampoco se encuentra feliz con su fortuna, y tan pronto como se ausenta el viejo da rienda suelta a sus maldiciones: "mal viejo, contrario de mi bien y sosiego, costal de güesos, ponzoña fiera, retablo de duelos, gruñidor" (id.). La acción continúa con el ruego de ayuda de la niña a Chuzón para que pueda ver a su doctor, "que me siento mala", dice, a lo que el bobo observa socarronamente que ha de ser por estar "enferma de la cintura para abajo" (p. 63). Chuzón escucha con toda caridad el ruego y realiza con toda eficacia su misión de celestino. A la llegada urgente del doctor la niña, con no poco descaro, exclama: "Norabuena te vea yo, doctor mío, medicina de mi herida"' (id.). Y sucede entonces el engaño, similar al que ocurre en El viejo celoso por ser una especie de engaño con la verdad. El bobo de la guarda ve a la niña gozar entre abrazos su medicina, pero cuando les confronta con su falta, Chuzón lo niega y la niña, con burlón ingenio propio de Sancho Panza, ofrece como explicación que la ventana desde la que dice haberlos visto "tiene encanto y está espiritada" (p. 64). Se efectúa la prueba de la ventana encantada y se renueva la burla. El licenciado aparece y desaparece con cada subida y bajada del bobo, y mientras éste queda convencido del poder y efecto mágicos de la ventana, la niña se ve felizmente desengañada y aliviada de su mal y de su herida.

El engaño con la verdad reside en este caso en hacerle creer al viejo, a su regreso, que vive engañado al tener celos de la niña, para lo que sirve de prueba la renovada experiencia de la ventana "espiritada", a la que él mismo asiste mientras la niña continúa con su curación.

El paralelo con el entremés de Cervantes es ahora fácilmente reconocible. Sin embargo, hemos de recordar una vez más que se trata de motivos folklóricos tradicionales de extensa raigambre, y que como afirma Asensio: "la esencia de los géneros literarios reside no en el asunto sino en el enfoque, no en el qué sino en el cómo" 11 . Los casos de maridos celosos y engañados gozan de gran auge en el Siglo de Oro, pero apenas hubiera merecido la pena traer a colación estas pequeñas joyas dramáticas si no fuera por la posibilidad que ofrecen de aproximarnos a $E l$ viejo celoso de

10 Cotarelo y Mori 1911 , t. 1, p. 62.

11 AsEnsio 1982, p. 27. 
Cervantes a la luz de otro tópico, el del viejo y la niña, y de otro motivo, el del incesto.

Como hemos sugerido antes, el núcleo de interés dramático y la fuente de comicidad fundamental no son únicamente, en mi opinión, los celos, el engaño' ${ }^{12}$, "la teatralización del adulterio"'13 o la condena de matrimonios sin amor y sin posible disolución ${ }^{14}$, sino la violación de un orden natural, el error en el que cae el viejo por exceso de confianza, y el abuso que comete por su vanidad y loco deseo. La raíz del conflicto reside en la incongruencia entre los dos papeles del viejo, el que desea o representa como esposo, y el de padre o guardián que le corresponde por su edad.

Lo que Cervantes hereda de la tradición burlesca de los maridos celosos no es simplemente una situación preñada de posibilidades cómico-dramáticas, sino un vehículo a través del cual dar expresión crítica de manera festiva a sus ideas sobre el amor, la libertad y la naturaleza humana. A este respecto viene como anillo al dedo lo que Parker observa sobre la filosofía del amor en Cervantes. En el debate sobre el amor entre Lerio y Tirsi que tiene lugar en La Galatea ya deja sentado Cervantes que el matrimonio y la razón son los únicos remedios disponibles para poder vencer la desordenada pasión amorosa, afirmando con ello a un tiempo, según Parker, que "one must not restrict or destroy freedom in order to prevent the evil it might commit" 15 . Y en el Persiles vemos cómo a través de la realización del ideal neoplátonico, que ama la belleza y la virtud capaces de inspirar un amor que ennoblece, Cervantes nos muestra que "[he] believed firmly in a pure love, and to that extent in a Platonic love, but directed towards marriage, which gives it dignity and permanence" 16 .

Las tres obras estudiadas nos han dado la oportunidad de apreciar la difusión del tópico del viejo y la niña y el influjo del motivo del incesto en una tradición cómico-folklórica, la del celoso, de gran interés y popularidad en el Siglo de Oro. Pero el entremés de Cervantes es "una amalgama de imaginación y verismo" y sus personajes "han cambiado enteramente de función"17. Importa reconocer, más particularmente, que la constante de la edad del celoso, el ser viejo, y su pasión por la niña, ya sea expresada

12 Casalduero 1974, p. 212.

13 Cannavaggio 1981, p. 27.

14 WARDROPPER 1981, p. 26.

15 Parker 1985, p. 119.

16 Ibid., p. 125.

17 ASENSIO 1973, p. 174. 
como deseo de posesión o como temor de pérdida en los celos, señalan una relación contra natura. El viejo, por edad y situación, adopta un papel ajeno, actuando no ya como esposo legítimo, sino como usurpador guardián, in loco parentis, a fin de gozar con exclusividad plena del amor de la niña. Esto da lugar a una relación que bien puede caracterizarse como incestuosa. Implica ésta además, como bien ha dicho Patricia Kenworthy, un desorden patente en la "unnatural nature of Cañizares' obsession"' 18 que hace preciso el irónico triunfo de la libertad y del instinto sobre la tiranía y la razón ${ }^{19}$. Pero ni el principio festivo que rige el entremés ${ }^{20}$, o ni siquiera "la despreocupación y desenfado" 21 con que se presentan las acciones, llegan a eclipsar el carácter aberrante del deseo del viejo y el abuso que sufre la niña, obligada a engañar con la verdad y a errar para desengañarse.

Como observara Asensio: "el teatro cómico no perdona los pecados contra la ley de naturaleza que subordina el matrimonio a la conservación de la especie y toma siempre partido por la mocedad" "22. Y es por ello que en el entremés de $E l$ viejo celoso, dentro de las coordenadas del género, Cervantes celebra el triunfo de la imaginación y da expresión a sus ideales sobre el amor y el matrimonio de manera más segura y abierta que en $\mathrm{El}$ celoso extremeño. Wardropper ha planteado la cuestión de la posible ambigüedad del entremés, en el que encuentra "little resemblance to the paradigm of comedy"'23. Y diría yo que, más allá de celos y adulterio, y como expresión de un orden social dislocado, tal ambigüedad obedece sin duda a la latente presencia del motivo del incesto, que caracteriza y da su valor exacto a las abusivas relaciones entre el viejo y la niña. La reconocida amoralidad del entremés expresa así un fondo moral grave a través del cual, y en el ámbito de tópicos y motivos tradicionales, se condena el serio error del viejo Cañizares y se celebra la liberadora imaginación de la niña Lorenza.

EDUARDO URBINA

18 Kenworthy 1979, p. 105.

19 Cf. ibid., p. 107; y WARDROPPER 1981, p. 26.

20 Clamurro 1982, p. 323.

21 Casalduero 1974, p. 213.

22 Aseisio 1973, p. 194.

23 WARDROPPER 1981, p. 25. 


\section{BIBLIOGRAFÍA}

I. TEXtos

ANÓNIMO

1911 Entremés de un viejo ques casado con una mujer moza, en Colección de entremeses, loas, bailes, jácaras y mojigangas desde fines del siglo $X V I$ a mediados del XVIII. Ed. Emilio Cotarelo y Mori. NBAE 17 , t. 1 , pp. $62-65$.

Cervantes, Miguel de

1982 El viejo celoso, en Entremeses. $3^{\text {a }}$ ed. Ed. Eugenio Asensio. Castalia, Madrid.

COTA, RODRIGO DE

1848 Diálogo entre el amor y un viejo, en LeANDRO FERNÁNDEZ DE MO. RATín, Origenes del teatro español. BAE 2, pp. 226-227.

ViCENTE, GiL

s.a.

O velho da horta, en Obras completas. Ed. Marques Braga, Sá da Costa, Lisboa, t. 5, pp. 141-176.

\section{Estudios}

Asensio, Eugenio

1973 "Entremeses", en Suma cervantina. Eds. J. B. Avalle-Arce y E. C. Riley. Tamesis, London, pp. 171-197.

1982 "Introducción crítica: los entremeses de Cervantes", en Mi guel De Cervantes, Entremeses. $3^{\mathrm{a}}$ ed. Castalia, Madrid, pp. $7-49$.

Bigeard, Martine

1972 Le folie et les fous littéraires en Espagne 1500-1650. Centre de Recherches Hispaniques, Paris.

Canavaggio, Jean

1981 "Estudio preliminar", en Miguel de Cervantes, Entremeses. Taurus, Madrid, pp. 7-34.

Gasalduero, Joaguín

1974 Sentido y forma del teatro de Cervantes. $2^{\hat{a}}$ ed. Gredos, Madrid.

Castro, Américo

1980 El pensamiento de Cervantes. Ed. ampliada y con notas del autor y de Julio Rodríguez-Puértolas. Noguer, Barcelona-Madrid, pp. 123-158.

\section{Cirot, Georges}

1929-1940 "Gloses sur les maris jaloux de Cervantes", BHi, 31, 1-74, 138-143, 339-346; 42, 303-306. 
Clamurro, William $\mathrm{H}$.

1982 "El viejo celoso y el principio festivo del entremés cervantino', $\mathrm{CH}(7), 317-324$.

Kenworthy, Patricia

1979

"The character of Lorenza and the moral of Cervantes' $E l$ viejo celoso", $B C, 31,103-108$.

Merimée, ERnEST

1930

A history of Spanish literature. Trad. S. Griswold Morley. Holt, New York.

Parker, Alexander A.

1985 The philosophy of love in Spanish literature (1480-1680). Ed. Terence O'Reilly. Edinburgh University Press, Edinburgh.

WARDROPPER, BRUCE

1981

"Ambiguity in El viejo celoso", Cervantes, núms. 1/2, 19-27. 